\title{
La ofensiva moralizadora y de control social en los espacios federales argentinos a comienzos del siglo XX: evaluación de sus alcances en el Chaco*
}

\section{Resumen}

Este artículo aborda el estudio de las medidas que se tomaron a principios del siglo XX para direccionar las actividades de recreación, esparcimiento y el comportamiento público en determinados espacios argentinos, con base a rígidos parámetros disciplinarios y morales. Se analiza el espíritu y contenido de leyes, resoluciones y Códigos que la dirigencia nacional de entonces promovió para que fuesen aplicados en las jurisdicciones federales en donde, por las características de sus cuerpos sociales todavía en formación, se presumían posibilidades exitosas de asimilación. Además, se explican los alcances de estas medidas, particularmente en uno de estos ámbitos de aplicación, el Chaco, con el propósito de proyectar sus efectos en otras jurisdicciones nacionales similares y dimensionar los resultados de conjunto.

\section{Palabras clave}

Tesauro: territorios nacionales, Chaco, control social, regulaciones. Autor: Argentina.

Referencia bibliográfica para citar este artículo: Mari, Óscar Ernesto. "La ofensiva moralizadora y de control social en los espacios federales argentinos a comienzos del siglo XX: evaluación de sus alcances en el Chaco". Anuario de Historia Regional y de las Fronteras 25.2 (2020): 119-147.

Fecha de recepción: 18/10/2019

Fecha de aceptación: 1/03/2020

Óscar Ernesto Mari: Doctor en Historia por la Universidad del Salvador. Investigador categoría Independiente del CONICET, Argentina. Profesor ordinario del Departamento de Historia de la Facultad de Humanidades de la Universidad Nacional del Nordeste, Chaco, Argentina. Código ORCID: 0000-00019803-7079. Correo electrónico: oscar.mari@yahoo.com.ar, iighi.secretaria@gmail.com.

\footnotetext{
* El presente artículo es el resultado de los trabajos de investigación realizados en el marco del Proyecto titulado: "Procesos de construcción de identidad vinculados a una actividad económica. El caso del algodón en el Chaco durante la etapa territoriana”, acreditado y con financiamiento parcial en la Secretaría de Ciencia y Técnica de la Universidad Nacional del Nordeste (Secyt-UNNE), con período de vigencia 2017-2020 (PI 16 S 001), del cual soy director responsable. Fue aprobado por resolución de RectoradoUNNE N ${ }^{\circ}$ 970/16 del 23 de noviembre de 2016.
} 


\title{
The Moralizing and Social Control Offensive Within the Argentine Federal Spaces at the Beginning of the 20th Century. Evaluation of its Scope in El Chaco
}

\begin{abstract}
This article addresses the study on the measures that were taken at the beginning of the 20th century to guide the activities of recreation, leisure, and public behavior in certain Argentine spaces, based on strict disciplinary and moral parameters. The spirit and content of laws are analyzed, as well as resolutions and codes that the national leadership of the time promoted in order to be applied in federal jurisdictions where, due to the characteristics of their social bodies still in formation, successful possibilities of assimilation were presumed. The scope of these measures is explained, particularly in one of these application areas - the Chaco, with the purpose of projecting their effects in other similar national jurisdictions, and dimensioning the overall results.
\end{abstract}

Keywords

Thesaurus: National Territories, Chaco, Social Control, Regulations.

Author: Argentina.

\section{A ofensiva moralizante e de controle social nos espaços federais argentinos no início do século XX. Avaliação de seu escopo no Chaco}

\section{Resumo}

Este artigo trata do estudo das medidas adotadas no início do século $X X$ para direcionar as atividades de recreação, lazer e comportamento público em determinados espaços argentinos, com base em rígidos parâmetros disciplinares e morais.Analisam-se o espírito e o conteúdo das leis, resoluções e códigos que as lideranças nacionais então promoveram para serem aplicadas nas jurisdições federais, onde, devido às características de seus corpos sociais ainda em formação, foram presumidas possibilidades de assimilação bem-sucedidas. $O$ escopo dessas medidas é explicado, particularmente em um desses campos de aplicação, o Chaco, com o objetivo de projetar seus efeitos em outras jurisdições nacionais similares e dimensionar os resultados gerais.

Palavras-chave

Tesauro: Territórios Nacionais, Chaco, Controle Social, Regulamentos. Autor: Argentina. 


\section{Introducción}

Hacia fines del siglo XIX, buena parte de los espacios federales de la República Argentina estaban conformados por los llamados “Territorios Nacionales", denominación que recibieron aquellas regiones periféricas que no formaban parte de las primeras provincias constituidas, y que luego de su creación formal, llegaron a representar más de la mitad de la superficie territorial del país. Desde luego, su respectivo proceso de organización e incorporación al Estado demandó un considerable esfuerzo en el que se ensayaron diversas fórmulas y normativas.

El origen de estos Territorios se remontaba a las inicialmente llamadas "Tierras Nacionales", que fueron motivo de disputas entre el Estado y las provincias a partir de 1862 . En ese año se dictó la ley número 28 por la cual se determinó que todos los Territorios existentes fuera de los límites de las provincias, pasaban a ser nacionales. En el marco de una progresiva centralización estatal se inició así un proceso de definición de la propiedad de estos vastos espacios periféricos situados en el norte y sur del país, y que por ese entonces se hallaban bajo dominio indígena y/o expuestos a las pretensiones de países vecinos.

Desde entonces, la incorporación efectiva de estas jurisdicciones a la Nación se demoró más de dos décadas en las que se alternaron campañas militares externas e internas, algunos diferendos limítrofes, y distintas configuraciones ordenadoras que culminarían finalmente con la sanción de la ley orgánica de los Territorios Nacionales en 1884 .

En el transcurso de este lapso, el Estado Argentino desplegó acciones de conquista militar, ocupación y poblamiento de estas tierras, algunas de las cuales se desarrollaron en forma simultánea. Libró en el norte una cruenta guerra con Paraguay en espacios geográficos que luego se convertirían en (tres) Territorios Nacionales, y además ensayó un primer intento de organización política y administrativa para algunas de estas jurisdicciones mediante la creación de las Gobernaciones de Chaco (1872), de la Patagonia (1878), y de Misiones en 1881, convirtiéndose estos ejemplos en los antecedentes más inmediatos de la norma definitiva que se sancionaría en 1884

La ley N. ${ }^{\text {a }} 1532$ de este último año dispuso la institucionalización de los Territorios Nacionales bajo una organización más precisa, pero que demostraba en alguna medida la temporalidad de esta condición como paso necesario para su ulterior conversión en provincias. Por ella se creaban nueve unidades territoriales a las que se dotaba de un régimen político uniforme y una delimitación más acotada, con lo cual quedaba regularizada la situación institucional de estas jurisdicciones. ${ }^{1}$

La originalidad de esta consistía en que estos espacios no se constituían como provincias, sino como "Territorios Nacionales", lo cual los colocaba bajo un ceñido tutelazgo estatal. Esta condición implicaba que sus autoridades eran designadas por el Poder Ejecutivo Nacional, y que sus habitantes tendrían derechos civiles, pero no políticos, salvo aquellos que podían ejercerse en los municipios constituidos.

${ }^{1}$ Los Territorios Nacionales creados por la ley 1532 fueron: La Pampa, Neuquén, Río Negro, Chubut, Santa Cruz, Tierra del Fuego, Misiones, Formosa y Chaco. 
De esta forma, durante esta etapa institucional, la administración de estas unidades estuvo a cargo de un gobernador que dependió directamente del Ministerio del Interior, y duraba tres años en el ejercicio de sus funciones. Era nombrado por el Poder Ejecutivo con acuerdo del Senado y estaba encargado como autoridad superior, de velar por el cumplimiento de las leyes y disposiciones nacionales. A las órdenes del gobernador se hallaba la policía territorial y un limitado plantel administrativo que se incrementó o disminuyó según las épocas, o bien de acuerdo a las características de gestión de cada gobernante. De todos modos, en general las funciones de los gobernadores fueron más de gestión que de resolución, y sus decisiones estuvieron casi siempre sujetas a la aprobación del Ministerio del Interior.

Si bien en la ley 1532 estuvieron previstas modificaciones a este restrictivo régimen a medida que se fueran dando ciertos progresos económicos y sociodemográficos, las mismas no pudieron hacerse efectivas, y solo se cambió este esquema recién cuando se produjo la provincialización de estos Territorios a partir los inicios de la década del cincuenta. De manera entonces que durante la mayor parte del período "Territoriano", los habitantes de estas jurisdicciones estuvieron reducidos a una condición de "ciudadanos de segunda categoría", lo cual en la práctica significó algunas desatenciones, o por lo menos, cierto desconocimiento por parte del Estado Nacional de las condiciones y modos de vida de estas sociedades en proceso de formación.

Ahora bien; cuando se estudian detenidamente las leyes, resoluciones y Códigos que se dictaron en la Argentina de fines del siglo XIX y principios del XX, y que estuvieron dirigidos especialmente a enmarcar jurídicamente a los recientemente organizados Territorios Nacionales y a reglamentar la coexistencia de sus cuerpos sociales, puede advertirse un acentuado interés por parte de los gobiernos centrales de entonces, de forjar dentro de estas jurisdicciones a sociedades que estuvieran asemejadas en la medida de lo posible a ciertos modelos europeos, en lo que respecta a normas de convivencia.

La dirigencia nacional de "notables" de esta época admiraba y procuraba emular algunos de estos valores "Victorianos" y por ello intentó transplantarlos en aquellos lugares de la República en donde, por las características de sus poblamientos y respectivos cuerpos sociales, existían buenas posibilidades de ser asimilados.

Estas condiciones se presentaban casi de manera ideal en los Territorios Nacionales, que estaban siendo poblados en buena medida con contingentes inmigratorios europeos, los cuales, sumados a la inmigración interna, conformaban nuevos y heterogéneos conjuntos en los que aún no existían prejuicios sociales ni identidades en común y, por tanto, podían ser permeables a un moldeado social por parte del Estado.

De esta forma, y a pocos años de haber sido sancionada la ley N. ${ }^{\circ} 1532$ que organizó con criterio uniforme a los Territorios, se encomendó a juristas reconocidos la tarea de redactar Códigos que serían utilizados específicamente en estos espacios, dadas sus características particulares en lo concerniente a situación geográfica, lejanía respecto a los centros más poblados o de decisión; composición de la población; pero, sobre todo, por tener problemáticas similares. 
Así surgieron, por ejemplo, el Código Rural en 1894, o el Código de Policía en 1908, los dos, orientados fundamentalmente a reglamentar las pautas de convivencia. Aún con sus importantes limitaciones, dichos instrumentos se convertirían en soportes referenciales para asistir a las autoridades en la prevención, tipificación, y/o penalización de contravenciones.

Pero paralelamente a la implementación de estos Códigos -que tuvieron estos exclusivos ámbitos de aplicación-, primó además la voluntad de promover normativas más amplias que incluían también a la Capital Federal. De todos modos, sus articulados parecieron estar dirigidos más bien a contemplar problemáticas que estaban especialmente extendidas en los Territorios Nacionales.

Dichas normativas apuntaron por lo general a regular, además de la convivencia, las conductas públicas, las reglas de higiene, de trabajo, y hasta los hábitos de recreación y esparcimiento, casi siempre influenciadas por los rígidos preceptos Victorianos.

Y así podemos hallar leyes y reglamentos que tendieron a controlar, entre otros varios asuntos, cuestiones como el alcoholismo, los juegos de azar, la prostitución, las actividades de recreación, todo ello siempre impregnado de una finalidad moralizante.

Para explicar esta ofensiva disciplinaria, en las páginas siguientes abordaremos en primer término el análisis de la ley N. ${ }^{\circ} 4097$ de juegos de azar sancionada en 1902, por la cual se prohibieron todas aquellas actividades lúdicas en las que corrían apuestas o premios, y no estaban explícitamente autorizadas por el gobierno central.

Comenzaremos por este tema porque esta ley, que tuvo aplicación en las jurisdicciones federales, es decir, en la capital y en los Territorios Nacionales, puso de manifiesto el pensamiento de la dirigencia nacional respecto a la línea que debía seguirse en la construcción de una ciudadanía alejada de vicios, y con normas de civismo similares a las existentes en las más destacadas sociedades europeas.

También, porque esta misma tónica impregnó en gran medida las disposiciones, e inclusive el contenido de Códigos contravencionales que se dictaron posteriormente, y porque las discusiones jurídicas acerca de su pertinencia e implementación en algunos lugares, preanunció en cierta forma el destino que tendrían en su momento reglamentaciones similares.

Seguidamente nos referiremos a la traslación de estas ideas a otros diversos aspectos de la vida de los habitantes de los Territorios Nacionales, que no solo tenían que ver con los juegos de azar y la recreación, sino también con las conductas que, en general, debían guardarse en el espacio público.

En este apartado analizaremos las disposiciones que, en tal sentido, fueron sistematizadas en Códigos reguladores como el Rural², y muy especialmente el

${ }^{2}$ Código Rural de los Territorios Nacionales. Edición original, y nueva edición con las modificaciones 
de Policía del año $1908,{ }^{3}$ por cuanto en ellos se vieron plasmadas de manera más explícita y detallada, las directrices moralizantes que por entonces emanaban desde la dirigencia nacional, pero también las consideraciones especiales que se tuvieron con los territorianos por tener una situación jurídica y realidades cotidianas bastante diferentes a las de sus connacionales de otras partes del país.

Finalmente, dedicaremos la última sección del trabajo a valorar los alcances y/o efectividad de estas medidas en uno de los Territorios Nacionales -el Chaco-, por cuanto entendemos que su proceso de poblamiento y evolución socioeconómica fueron representativos de lo ocurrido en otros, lo cual permite transpolar una evaluación similar en lo que respecta a los resultados finales de estas políticas disciplinares.

Figura N 1: Mapa de la República Argentina durante la primera década del siglo XX. Superficies de las primeras provincias constituidas y de los Territorios Nacionales.

introducidas por las leyes de 16 de septiembre de 1910, y 28 de febrero de 1917. (Buenos Aires, J. Lajouane \& Cía Editores, 1922).

${ }^{3}$ Código de Policía para los Territorios Nacionales de la República Argentina. (Buenos Aires, Imp. de Juan Alsina, 1908). 


\section{El espíritu y los alcances de la Ley de Juegos de Azar de 1902}

Aunque no es la única cuestión dentro del abanico de temas que intentamos tratar en este trabajo, consideramos importante abordar en primer lugar el análisis de la ley de "Juegos de Azar" sancionada en 1902, porque precisamente su contenido nos revela el pensamiento de la dirigencia de ese entonces y sus objetivos en cuanto a los principios que debían regir las normas de conducta de una sociedad nacional todavía en vías de formación. Cabe destacar además que mucho del espíritu que animó esta ley se trasladó luego a la redacción del ya mencionado Código de Policía de 1908; a las reglamentaciones y ordenanzas municipales territoriales y a la tónica de los procedimientos policiales de la época.

La ley N. 4097 de Juegos de Azar puesta en vigor el 06 de agosto de 1902, fue promovida por el entonces Senador Carlos Pellegrini, quien había sido presidente de Argentina entre 1890 y 1892. Según justificaciones de ese momento, la misma tuvo “[...] el propósito moralizador de cortar con mano eficaz no solo la explotación del azar en todas sus formas clandestinas, sino también el de obstruir todo acto tendiente a incitar o cultivar el sentimiento o la inclinación al juego". ${ }^{4}$

En apoyo a su sanción, Pellegrini había expresado: "Lo que la ley 4097 trata de limitar no es el juego, pues nuestra legislación siempre ha sido contraria a estos principios de tutela individual... Lo único que castiga o trata de disminuir o suprimir, es el vicio clandestino, es la incitación al vicio, y es la explotación del vicio".5

Y continuó: “[...] esta ley nace a consecuencia de que la penalidad actual ha hecho pulular una infinidad de pequeñas explotaciones al juego, de ese juego que seduce a las clases más fáciles de seducir, a las clases bajas, a las clases ignorantes, al pueblo trabajador, a los menores de edad". ${ }^{6}$

Pero en rigor de verdad, esta ley literalmente prohibía "todos los juegos de azar", e incluso los de "destreza" que no fuesen autorizados expresamente por el gobierno nacional, estableciendo penas pecuniarias y/o arresto a quienes transgredieran la norma. Se incluían dentro de la figura de infractores tanto a los participantes en los juegos, como a los ocasionalmente presentes; a los dueños de los recintos, anunciantes o patrocinadores, y sus ámbitos de aplicación serían la capital federal, y los Territorios Nacionales.

Como dato curioso cabe consignar que se estableció que lo recaudado en concepto de multas sería destinado a entidades de beneficencia de la capital y los Territorios Nacionales que estuvieran autorizadas por la Lotería Nacional, lo cual a la

\footnotetext{
${ }^{4}$ Máximo Reyna, Territorios Nacionales. Leyes y decretos sobre su administración y resoluciones varias aplicables a los mismos (Buenos Aires, Ministerio del Interior, 1910) 753.

${ }^{5}$ Reyna 753.

${ }^{6}$ Reyna 753.
} 
postre resultó contradictorio, ya que como veremos, esta ley se invocó frecuentemente para prohibir incluso hasta los sorteos benéficos que organizaban estas instituciones con fines de bien público.

Cuando mencionamos esta ley, lo que buscamos es dimensionar sus alcances reales y aplicación dentro de un plan moralizante que llevó en no pocos casos a imposiciones exageradas $\mathrm{y}$, a veces, hasta ridículas. Y pueden consignarse varios ejemplos en este sentido.

En 1902, por caso, hubo algunos planteos jurídicos acerca de la constitucionalidad de la ley y/o la pertinencia de declarar como contravenciones a ciertos entretenimientos, premios o sorteos ofrecidos por productos comerciales o entidades de beneficencia.

Uno de los casos más sonados en ese momento fue el que motivó el multado de quienes fueron encontrados practicando los juegos conocidos como "Lansquenet" y "Guitarrita"7 en lugares que no eran precisamente garitos o destinados exclusivamente a juegos de azar, sino clubes sociales en donde las actividades principales eran fundamentalmente deportivas, como lo fueron por ejemplo, las entidades "Fraternidad", "Unión Uruguaya", o el club "Velocipédico Argentino", entre otros, todos ellos de capital federal.

En ese entonces los debates se centraron en torno a si era procedente sancionar también a personas que estaban jugando a los naipes como parte de sus reuniones de sociabilidad o camaradería -como en este caso-, ya que algunos estimaban que esta actividad no era la finalidad última ni principal en estos sitios, como sí lo era cuando se ingresaba en una "casa pública" de juego.

La falta de acuerdo sobre estos puntos motivó, por ejemplo, que los jueces que trataron casos similares interpretaran de manera totalmente opuesta los alcances de la ley, y fallaran condenando -o absolviendo- a los acusados, por la supuesta comisión de la misma infracción.

Otro caso por destacar es el que se produjo en 1905 cuando se constató que algunas marcas de cigarrillos ofrecían premios a los consumidores de acuerdo con la acumulación de los "vales" que estaban contenidos dentro de sus paquetes y que se denominaban premios "réclame".

En este sentido hubo extensas argumentaciones de juristas que opinaron a favor y en contra de multar a las cigarreras. La cuestión, nuevamente, era definir si este tipo de incentivos a la compra se encuadraban dentro de los juegos de azar prohibidos por la ley 4097.

\footnotetext{
${ }^{7}$ El "Lansquenete" era un juego de azar surgido en el siglo XV de características similares al póquer, y difundido por los "lansquenetes", (mercenarios) de origen alemán. No hemos encontrado referencias del juego llamado "guitarrita", pero de todos modos, ambos están en desuso.
} 
En este episodio -de discusiones extensas y ciertamente desproporcionadaspodemos apreciar otra vez las exageraciones en las que se incurría al interpretar una ley que era claramente deficiente en sus términos. A tal punto se discutió el asunto que el propio presidente de la República Manuel Quintana -aconsejado por el procurador de la nación-, debió definir y se pronunció emitiendo una resolución final en donde se ordenaba la prohibición de esta práctica, y se multaba a las compañías involucradas. ${ }^{8}$

Pero la ofensiva no terminó allí. La vocación persecutoria afectó incluso a Asociaciones Mutualistas de importantes colectividades de inmigrantes, las mismas a las que supuestamente se quería beneficiar derivándoles las recaudaciones obtenidas en concepto de multas.

El caso que relatamos ahora ocurrió en mayo de 1908 cuando la policía denunció a los círculos "Valenciano" y "Gallego" de la capital federal, de ser centros clandestinos de juego, aunque esta vez los socios afectados fueron sobreseídos por falta de pruebas convincentes. Aquí también, desde luego, se produjeron las consabidas argumentaciones de los abogados intervinientes. ${ }^{9}$

Esta onda controladora se acrecentó durante los meses siguientes, en los que directamente se adoptó un esquema "preventivo" de prohibiciones, denegándose permisos para realizar sorteos con premios a las asociaciones "La patria degli italiani" y "corriere d' Italia", e incluso para organizar kermeses con fines de caridad, tal como ocurrió con los pedidos de las asociaciones "Próceres de la independencia"; "Socorros mutuos Roma", y la congregación "Hijas de María del huerto", todas ellas de capital federal. ${ }^{10}$ A este punto había llegado la manía moralizante en la Argentina; y por otra parte, ¿qué ocurrió con las otras cuestiones catalogadas como prohibidas en la ley 4097 de juegos de azar?

Hablemos por ejemplo de las carreras de caballos, mencionadas también en la ley, que desde luego eran una actividad ampliamente difundida en todo el país prácticamente desde los orígenes de su poblamiento.

Su práctica regular formaba parte de las actividades de destreza o esparcimiento tanto en los ámbitos urbanos como rurales $\mathrm{y}$, por tanto, estaba íntimamente arraigada en la identidad popular, habiéndose mantenido vigente a lo largo de todas las épocas.

Pero al margen de la competencia ecuestre en sí misma, motivada muchas veces por desafíos relativamente espontáneos, lo cierto es que pocas veces se disputaban sin que hubiera apuestas de por medio, lo cual tornaba más emocionante a la contienda. Y no estamos hablando de carreras con cierta organización y en las que intervenían varios ejemplares equinos. Hablamos de las sencillas "carreras

\footnotetext{
${ }^{8}$ Para ampliar sobre estos intercambios de opiniones, véase su transcripción en: Reyna 754-755.

${ }^{9}$ Reyna 756-757.

${ }^{10}$ Reyna 757-758.
} 
cuadreras" que se disputaban entre dos jinetes solamente y en tramos cortos, de cien a cuatrocientos metros. Aquí también proliferaban las "paradas" de los concurrentes, que hallaban en este espectáculo generalmente dominguero, un recreo atrapante para la monotonía de sus vidas diarias.

Pero entonces vino la ley 4097, que en sus artículos $3^{\circ}$ y $7^{\circ}$ establecía, entre otras cuestiones que:

[...] pagarán una multa de $2.000 \$ \mathrm{~m} / \mathrm{n}$, o en su defecto arresto por un año, las personas que en cualquier sitio explotaren apuestas sobre carreras de caballos"(art $\left.3^{\circ}\right)$, y que "[...] ningún campo de carreras podrá ser abierto al público sin autorización del Poder Ejecutivo, que solo permitirá las carreras de caballos que tengan por fin exclusivo la mejora de la raza caballar y sean organizadas por sociedades cuyos estatutos sociales hubieren sido previamente aprobados $\left(\operatorname{art} 7^{\circ}\right) .{ }^{11}$

Indudablemente el espíritu de esta ley buscaba evitar la proliferación de actividades apostadoras, fundamentalmente por las consecuencias que casi de forma irremediable se producían en la alteración del orden público cuando estas se daban en ámbitos clandestinos, es decir, por fuera de entidades organizadas con estatutos y reglamentos. Y desde luego, la mayoría se producían de esta forma. En los ámbitos rurales no abundaban las instituciones sociales organizadas.

Pero "prohibir" la actividad implicaba necesariamente contar con la estructura de vigilancia y los pertinentes recursos humanos para garantizar su cumplimiento, y pareciera ser que aquí no se contemplaron las limitaciones existentes, sobre todo en los ámbitos rurales de los Territorios Nacionales, en donde no existían los mínimos controles, y en los que, quienes debían imponerlos, a menudo se involucraban en la misma actividad ilícita que debían impedir.

Esta prohibición suscitó las esperables controversias y luego, las lógicamente oscilantes políticas de control, sobre todo, en los Territorios Nacionales.

Respecto a lo primero, ponemos como ejemplo la posición sostenida por el procurador general al aconsejar en 1905 al presidente de la Nación para "[...] que no autorice la vigencia de una ordenanza de la localidad de General Roca ${ }^{12}$ para organizar carreras de caballos", vulnerando con ello y sin pruritos, la autonomía municipal para dictar ordenanzas de alcance comunal.

En sus fundamentos, y respecto a lo esgrimido por el Municipio que decía organizar esta carrera para "[...] fomentar la agricultura y la ganadería", el funcionario sostenía que "[...] ni la ley general de Territorios Nacionales $\mathrm{N}^{\circ} 1532$, ni la $\mathrm{N}^{\circ} 2735$ que la modificó en parte, autorizan a las municipalidades a emprender fomento alguno", y que sus facultades estaban limitadas a "[...] proveer la vida comunal, la imposición, y percepción de cargas”. En suma, agregaba que:

\footnotetext{
${ }^{11}$ Ley de Juegos de Azar No 4097, 09 de agosto de 1902.

${ }^{12}$ Localidad del entonces Territorio Nacional de Río Negro.
} 
[...] en ninguna población dispersa de los Territorios Nacionales existen elementos necesarios para la mejora de la raza caballar que por las carreras se obtiene, y que ni sus rudimentarias autoridades, ni sus municipalidades limitadas estaban en condiciones de iniciar, dirigir y costear ese fomento por falta de representación, autoridad y recursos [...], por lo cual faltaría el motivo exclusivo que la ley 4097 acepta para permitir las carreras de caballos [...]. ${ }^{13}$

Aun así, el presidente Quintana tomó este dictamen como válido y ordenó notificarlo a los gobernadores de todos los Territorios Nacionales para su efectivo cumplimiento. ${ }^{14}$

Pero esta disposición, a la que se le agregarían otras tantas durante los años siguientes y estarían también incorporadas a códigos como el de Policía de 1908, tendría, como todas, el mismo destino (interpretable) durante la vigencia de los Territorios Nacionales.

En el caso del Chaco, por ejemplo, las carreras de caballos se prohibieron y se autorizaron con errática intermitencia, y en perfecta sintonía con los variables escrúpulos -o intereses- de cada gobernador de turno. A la sazón, las respectivas tónicas de gobierno en uno $\mathrm{u}$ otro sentido impregnan casi enteramente los partes policiales, ordenanzas, y disposiciones de las gobernaciones durante casi toda la época territoriana.

Las carreras de caballos continuaron así realizándose legal, clandestina o subrepticiamente, y a veces también camufladas detrás de inocentes actividades con fines benéficos, con la oscilante persecución, anuencia, o bien, el inocultable regenteo por parte de la autoridad policial, según los casos y circunstancias.

\section{La extensión de estas ideas a otros diversos aspectos de la vida cotidiana en los Territorios Nacionales}

Ahora bien, ¿qué ocurrió a raíz de esta cruzada moralizadora con los demás aspectos de la vida de los territorianos, que es en buena medida un tema que también nos interesa reconstruir? Para responder a esta inquietud debemos retrotraernos a un tiempo anterior al momento en el que se sancionó la ley 4097, y describir con cierta aproximación cómo era la vida de los residentes, y con base a qué legislación reglaban sus pautas de convivencia.

En tal sentido debemos recordar que estos espacios tuvieron una organización política e institucional tutelada por el poder central. Si bien con cierto número de habitantes podían constituirse municipios electivos, y al llegar a los sesenta mil quedaban habilitadas para convertirse en nuevas provincias, en la práctica solo se cumplieron parcialmente estas disposiciones, de modo tal que la mayoría permaneció

\footnotetext{
${ }^{13}$ Nota del Procurador General de la Nación, Julio Botet. En: Reyna 755.

${ }^{14}$ Resolución del Poder Ejecutivo Nacional del 19 de septiembre de 1905 con base al dictamen del Procurador General de la Nación, Julio Botet.
} 
casi en completa dependencia de las autoridades centrales hasta la década del cincuenta del siglo XX en que fueron provincializados gradualmente.

El poblamiento "blanco" de los mismos se hizo en buena medida con contingentes inmigratorios provenientes de Europa, que desde distintos países y en diferentes momentos llegaron para radicarse fundamentalmente en los ámbitos rurales de estos nuevos espacios.

Como consecuencia de tener procesos de poblamiento intensivos, de carecer de comunicaciones adecuadas, de autoridades competentes y de existir en varios de ellos también el riesgo latente de ataques indígenas aún no asimilados totalmente, la vida en estas jurisdicciones fue muy distinta a la de otras que habían sido organizadas con anterioridad, como las provincias por ejemplo. A menudo expuestos a condiciones de vulnerabilidad y de alta dependencia en diversas materias, los territorianos precisaron, por tanto, atenciones especiales en función de sus realidades particulares. Si se había hecho una ley de organización particularizada, de la misma manera había que complementarla con normativas adicionales específicas para estas unidades territoriales.

De esta forma, -y tal como mencionáramos al comienzo del presente-, prontamente se comprendió la necesidad de confeccionar Códigos especiales para uso exclusivo en los Territorios Nacionales, dadas sus problemáticas singulares.

Así en 1894 se puso en vigencia el "Código Rural para los Territorios Nacionales", el cual con sus posteriores modificaciones de 1910 y 1917 fue el instrumento más utilizado -o por lo menos invocado- para regir la convivencia entre los territorianos, especialmente en los ámbitos no urbanos, en donde residía la mayor parte de la población.

Dicho Código brindó una imprescindible referencia para tipificar contravenciones, posibilitando con ello una intervención más adecuada de las autoridades y evitando los procedimientos de criterio personal. Pero con el paso del tiempo y su uso habitual, quedó en evidencia que sus disposiciones estaban redactadas en términos muy generales. Los vacíos que quedaron sobre algunas cuestiones, y sus imprecisiones en materia de procedimientos policiales hicieron pensar al poco tiempo en la necesidad de confeccionar un nuevo Código que enmendase particularmente estas últimas deficiencias.

Por ello en 1906 se encomendó a Gabriel Carrasco la redacción de un "Código de Policía" que estaría destinado a ser utilizado exclusivamente en los Territorios Nacionales. El mismo entró en vigor en 1908 y tuvo el propósito de complementar y/o reemplazar en determinados casos al escueto Código Rural, ya que poseía un articulado más completo. ${ }^{15}$

${ }^{15}$ El Dr. Gabriel Carrasco, abogado, desempeñó numerosas funciones públicas en su provincia natal, Santa Fe, y en el ámbito nacional. El 27 de noviembre de 1888, el Gobernador Dónovan puso en vigencia el 
Una novedad de esta nueva reglamentación fue que se dotó a las policías territoriales de mayores facultades en sus procedimientos, dada la lejanía o directamente ausencia de autoridades judiciales. Ello generaría a su vez y con el transcurso del tiempo nuevos problemas que habrían de ser característicos de los Territorios Nacionales, y que fueron precisamente los excesos en los que cayeron las policías locales.

La importancia de estos dos códigos reside en que, a través de la lectura de sus artículos, podemos recrear de manera bastante aproximada los modos de vida que tenían los residentes de estos espacios, y también intuir desde qué óptica -y con qué valoraciones- eran vistos por la dirigencia nacional de esa época.

Precisamente en el contenido de estos códigos -mucho más en el segundo-, se puede entrever el modelo de sociedad que se deseaba forjar con estos nuevos conjuntos humanos, los que por su heterogeneidad y escasa cohesión aún podían ser moldeados por el entonces imaginario gubernamental. Y en este sentido, particularmente el Código de 1908 es pródigo en ejemplos acerca de cómo los territorianos debían desenvolver su convivencia con base a reglas morales y buenas costumbres "marcadas" desde el poder central.

Es justamente en la tercera sección de este Código en donde se establecen los procedimientos que deberán cumplirse frente a cuestiones como la ebriedad y las conductas públicas en general; los juegos de azar, las actividades de recreación, las reuniones colectivas, y otras tantas inherentes al comportamiento de las personas en los espacios comunes.

Respecto al tema del excesivo consumo de alcohol, debe recordarse que esta problemática fue motivo de preocupación para autoridades locales y nacionales prácticamente desde el nacimiento de estas jurisdicciones periféricas.

Muchos coincidieron en advertir las consecuencias negativas que este hábito acarreaba para el desarrollo normal de las faenas laborales; para la limitada capacidad de control social de la administración territoriana, y para la salud de los trabajadores. Respecto al tema, ya en 1914 el inspector del Departamento Nacional del Trabajo José Elías Niklison daba cuenta de la generalización del problema al describir, por ejemplo, al trabajador común de los obrajes forestales:

[...] su salud es generalmente buena hasta los venticinco o treinta años, pasados los cuales, por efecto de las afecciones venéreas, abusos del alcohol, y defectos de alimentación, se observa una decadencia física que los predispone a la

primer Código de Policía Urbano y Rural para el Chaco, redactado por él. El Dr. Gabriel Carrasco dejó escritas conferencias y cartas de gran valor histórico, como "La Provincia de Santa Fe y el Territorio del Chaco" (conferencia pronunciada en el Instituto Geográfico Argentino el 22/04/1887) y "Cartas de viaje por el Paraguay, los territorios del Chaco, Formosa y Misiones y las Provincias de Corrientes y Entre Ríos" (Bs. As. - 1889). Falleció en Buenos Aires el 5 de junio de 1908. Lidia Polich de Calvo, Hombres y Mujeres que Hicieron Chaco (Encarnación, Paraguay, Editorial Talleres Gráficos de Imprecop, 1996) 49. 
La ofensiva moralizadora y de control social en los espacios federales argentinos...

tuberculosis". ${ }^{16}[\ldots]$ Tampoco es raro encontrar niños bebiendo en las pulperías de los obrajes a la par de los hombres. El alcohol hace estragos en la región, predisponiendo a los hombres a enfermedades graves, y a peligrosos estados de ánimo. ${ }^{17}$

Sin embargo, el código de 1908 abordó el problema desde el punto de vista moral y disciplinario, enfocándose casi exclusivamente en la irresponsabilidad de las personas apegadas al vicio. Por ejemplo, cuando se refiere al tratamiento de la ebriedad en los ámbitos públicos y a los protocolos y penas que debían ejecutarse en caso de constatar la contravención, ${ }^{18}$ el articulado declaraba ante todo que frente a infracciones o delitos de cualquier índole "[...] la embriaguez sería considerada siempre como circunstancia agravante $[\ldots]$ ". ${ }^{19}$

Dicho esto, precisaba que serían penadas con multas de diez pesos las personas que fueren encontradas ebrias en cualquier sitio público. La misma suerte correrían los almaceneros que les permitiesen ingresar a sus locales estando ya alcoholizadas; quienes faciliten su consumo a gendarmes, policías o menores de dieciséis años, y aquellos que no exhibiesen estas advertencias escritas en sitios bien visibles de sus respectivos establecimientos. En caso de reiterarse la infracción por ebriedad, los acusados sufrirían un arresto de diez días, trasladándose a los mismos "[...] sin escándalo público". ${ }^{20}$

Respecto a las reglas de convivencia, el articulado de este Código pareció considerar solo aquellas situaciones que eventualmente se produjeran en espacios con cierta densidad poblacional, ya que su contenido presupone casi siempre la existencia de una concurrencia que no podía darse en los ámbitos enteramente rurales.

Así vemos que, con referencia a las potenciales contravenciones en que se podía incurrir y sus respectivas penas, se estipulaba por ejemplo que “[...] tendrán un arresto de hasta veinte días, los que causaren desorden o perturbaren reuniones, fiestas o ceremonias, con petardos, pitos u otros ruidos [...]; los dueños o responsables de casas en cuyo interior se produzcan reuniones bulliciosas y pendencias originadas por el libertinaje, el juego, o la bebida $[\ldots]$ ". ${ }^{21}$

\footnotetext{
${ }^{16}$ República Argentina. Informe del Inspector del Departamento del Trabajo, José Elías Niklison. Boletín del Departamento Nacional del Trabajo N. ${ }^{\circ} 32,(1915): 125$.

${ }^{17}$ Niklison 131-132.

${ }^{18}$ Cabe recordar que en este código se facultó a las policías territorianas para aplicar penas. La razón invocada fue que: "[...] en las inmensas soledades de los Territorios Nacionales, allí donde no existe otra autoridad que el comisario de policía y donde una consulta requiere hasta meses para ser respondida, se necesita contar con el amparo relativamente inmediato de esta autoridad [...]". Código de Policía, Libro II, p. XIV).

${ }^{19}$ Código de Policía, Libro III, 73.

${ }^{20}$ Artículos $\mathrm{N}^{\circ} 420$ a 429 del Código de Policía, Libro III, Capítulo II, 84.

${ }^{21}$ Artículos No 397 a 400 del Código de Policía, Libro II, Capítulo I, 79-80.
} 
De la misma forma se indicaba que cometían desórdenes y escándalos aquellas personas que en parajes o reuniones públicas "[...] profieran palabras indecorosas, gritos de muerte, o que ejecuten actos obscenos u ofensivos a la moral pública [...]"; las que en teatros, circos o espectáculos "manifiesten su aprobación de manera excesiva [...]"; las que "provoquen o acepten altercados en alta voz [...]"; las que "se bañen en sitios públicos sin estar cubiertos con la ropa o traje que la honestidad reclama [...]"; las que "provocan alarmas infundadas en sitios concurridos [...]"; las que "cantan, gritan o tañen instrumentos de una manera desordenada o hacen ruidos molestos [...]"; las que "promueven cencerradas o asisten a ellas $[\ldots]$ ". ${ }^{22}$ En todos estos casos, los infractores serían multados con hasta treinta pesos. ${ }^{23}$

Así mismo, serían penadas con cinco a veinticinco pesos de las personas que "[...] escriban palabras o pinten objetos deshonestos o inmorales en las paredes u otros sitios públicos [...]"; las que "profieran palabras obscenas o cantos inmorales [...]", ${ }^{24}$ lo cual denota claramente la voluntad de establecer una estricta disciplina social bajo la amenaza de sanciones ejemplificadoras a transgresiones verdaderamente insignificantes.

Pero curiosamente, y con una notable desproporción en la valoración de las contravenciones, dentro de las normativas dispuestas para el comportamiento público se incluían también las inherentes a la portación y uso de armas.

Respecto a este tema, ya en el código rural de 1894 se había dispuesto un régimen especial para los habitantes de los Territorios Nacionales en vista de los peligros que afrontaban cotidianamente, y que ya no existían en otras jurisdicciones nacionales. En aquel momento se dispuso que "[...] la policía no podrá prohibir o restringir el derecho de llevar armas y, en consecuencia, ninguna persona será registrada con el objeto de averiguar si lleva armas consigo [...]". Pero aclaraba luego “[...] es prohibido sin embargo hacer ostentación de armas o llevarlas a la vista, bajo pena de 10 pesos de multa $[\ldots]]^{25}$

En el Código de 1908, y a raíz de los hechos de sangre que ocurrían por esta permisividad, se procuró brindar precisiones más específicas acerca de los alcances del derecho a portar armas -sobre todo, las de fuego-. Por ello hay un extenso articulado más sus respectivos incisos, que intentan evitar excesos en esta materia.

\footnotetext{
${ }^{22}$ Las cencerradas eran una manifestación burlesca de tradición ibérica. Consistía en el agrupamiento de personas que, con cencerros, hacían un estrépito frente a la vivienda de un recién casado cuando las diferencias de edad de la pareja eran muy acentuadas, entre otros motivos.

${ }^{23}$ Artículos $\mathrm{N}^{\circ} 430$ al 432 del Código de Policía, Libro II, Capítulo II, sección II, 85-86.

${ }^{24}$ Artículos N 462 a 465 del Código de Policía, sección VII, 94.

${ }^{25}$ Artículos № 253 y 254 del Código Rural para los Territorios Nacionales. En 1918 se intentó reformar nuevamente el Código Rural y se puso especial énfasis en la reconsideración de estos artículos. En el proyecto de reforma se explicaba que: "[...] dado el despoblamiento que existe en los territorios nacionales, no nos ha parecido prudente prohibir la portación de armas en la campaña, pero sí en los lugares poblados. El Código actual no hace diferencia alguna sobre el particular, sin duda porque cuando se sancionó, había un número muy reducido de pueblos en los territorios [...]". República Argentina. Archivo General de la Nación (AGN). Memoria del Ministerio del Interior 1919-1920, inédita, 338.
} 
Si bien se mantuvieron ciertas premisas, como por ejemplo la continuidad de la autorización para la libre portación de armas y la prohibición de catear a los habitantes para constatar si las llevaban consigo, se detallan ahora con mayor meticulosidad con qué acciones y en qué circunstancias se caía en la "ostentación”, y consecuentemente, en el abuso de esta licencia, lo cual era punible.

Dentro de las novedades observadas, se destaca ahora la autorización para que menores de dieciséis años puedan portar armas de fuego, pero con el consentimiento escrito de sus padres. ${ }^{26}$ De todos modos, las penas para los infractores eran en general muy bajas si se las compara con las asignadas a otras contravenciones aquí tratadas.

Pero, aunque pueda parecer contradictorio, el tratamiento de estos últimos artículos tal vez haya sido el de mayor sentido común en relación a las problemáticas reales de los territorianos.

Y aquí llegamos a uno de los puntos de este Código que es de gran interés para el tema que nos ocupa, cual es la sección destinada a reglamentar las actividades de esparcimiento, por cuanto ello no solo nos revela en buena medida varios aspectos de la vida cotidiana de los territorianos, sino también aquello que reviste suma importancia en este artículo, y que consiste en exponer la intención estatal de moldear a estos nuevos conjuntos sociales con parámetros foráneos, muchas veces discordantes con la realidad del país.

Es revelador, por tanto, el resumen de lo establecido en torno a temas tales como los juegos de azar, los eventos de concurrencia masiva, y hasta el ejercicio del meretricio, que por entonces se hallaba reglamentado y estaba tácitamente encuadrado dentro de las actividades recreativas.

Respecto al primer punto debe remarcarse que en esta codificación se hizo una explícita diferenciación entre los juegos prohibidos y aquellos que estaban permitidos, aunque estos últimos también merecieron algunas restricciones.

Dentro de los permitidos se consignaban los que se desarrollaban en ámbitos controlados o cerrados respetando reglamentaciones, como por ejemplo las carreras pedestres o de bicicleta; la sortija o carreras ecuestres; bochas, pelota o billar, y en fin, todos aquellos en los que se ponía a prueba la destreza, fuerza o habilidad de los intervinientes.

Estaban prohibidos, sin embargo, aquellos que solo dependían de la suerte, y en donde no contaba la fuerza ni la habilidad de los jugadores, como podían ser por ejemplo los juegos de loterías no autorizadas, rifas, naipes, dados, o el de la taba. ${ }^{27}$ También se consideraban prohibidos aquellos entretenimientos que implicaban

\footnotetext{
${ }^{26}$ Artículos $N^{\circ} 407$ a 419 del Código de Policía., sección II, 81-84.

${ }^{27}$ El juego de la "taba" se hace arrojando a cierta distancia el hueso de la pata del vacuno que lleva ese nombre y que tiene dos caras. Una de esas caras se llama "suerte", y si cae para arriba, otorga esa condición
} 
combates entre o con animales, como las riñas de gallos, las cinchadas de caballos, o la lidia de vacunos.

Obviamente, todos estos juegos prohibidos por el Código de 1908, y que lo estaban en buena medida por lo ya dispuesto por la ley 4097 seis años antes, tenían una amplia difusión en los Territorios Nacionales.

El inspector Niklison supo dar prueba de ello al elevar su informe al Poder Ejecutivo en 1914. Refiriéndose a lo que observó en los típicos “obrajes” del Chaco acerca de algunos de estos juegos, afirmó que ellos eran el medio más eficaz que tenían los sufridos labradores para evadirse por algunos momentos de "[...] sus tristes vidas, sin goces ni halagos". Se explayó luego diciendo: “[...] la pasión por el juego se ha generalizado en la región [...] Juegan a los naipes, a la taba, a la moneda arrojada al aire, a cualquier cosa que les sirva para ganar, o producir las emociones buscadas con avidez". ${ }^{28}$

De este modo, al menos en los ámbitos rurales y lejos del control de las autoridades resultaba difícil la aplicación, o siquiera, que fuese conocido un articulado como el expuesto en el Código de 1908.

Ahora bien, en referencia a los juegos autorizados por el mismo, se establecía que se permitían "toda clase de juegos y diversiones honestas", pero se dejaba muy en claro que "se castigaría el abuso de ellos". ${ }^{29}$

De esta última salvedad derivaron precisamente algunas restricciones que llegaron a bordear el ridículo, como por ejemplo aquellas que pretendieron encorsetar ciertos juegos infantiles como el del barrilete o las bolitas (canicas), cuando estos implicaran incomodidades para el vecindario, o se convirtieran en un peligro para otros. En tales casos, pasaban a considerarse como "abusivos". ${ }^{30}$

La misma impronta intentó aplicarse respecto a la recreación de los adolescentes cuando se estableció que "[...] los menores de quince años que se encuentren en las calles y plazas molestando con sus juegos, pronunciando palabras obscenas, rayando las paredes o cometiendo cualquier clase de actos indecorosos, serán aprehendidos y entregados a sus padres o tutores, quienes pagarán una multa de

\footnotetext{
al jugador. Hasta hoy se sigue practicando en los ámbitos rurales de Argentina.

${ }^{28}$ Niklison 133

${ }^{29}$ En el artículo N. ${ }^{\circ} 436$ del Código de Policía se declaraban como abusivos: "Toda clase de juegos de azar en que se arriesgue dinero o cosa que lo valga [...]; toda clase de juegos, incluso los no prohibidos, si se efectúan por dinero o cosa que lo valga [...]; Las carreras, sortijas y demás juegos que se efectúen al aire libre y provoquen gran concurrencia de gente, si tienen lugar en días no festivos, sin permiso de la autoridad [... " "Véase también artículos N. ${ }^{\circ} 433,434$, y 435 del Código de Policía, 87-88.

30 “ $[. .$.$] los juegos propios de los niños, como el barrilete, bolita y demás, que pueden considerarse como un$ ejercicio higiénico moderado o diversión honesta, no serán abusivos, salvo cuando se realicen en las calles, plazas o sitios que constituyan una incomodidad para el vecindario, o un peligro para otros..." Artículo N. ${ }^{\circ}$ 444 del Código de Policía,90.
} 
dos a diez pesos". ${ }^{31}$ Nuevamente aquí se observa otra idealización en el articulado de este Código: se daba por sentado que todos los adolescentes tenían padres o tutores.

De todas formas, pareciera ser que solo en los ámbitos urbanos podía haber posibilidades de, por lo menos, invocar la existencia del Código para controlar el comportamiento público de las personas.

Por ejemplo, con respecto a las diversiones que suponían aglomeraciones, el Código de 1908 se ocupó de reglamentar entre otras actividades, los bailes y espectáculos de nutrida concurrencia, aunque se aclaraba que su aplicación se haría únicamente en aquellos poblados que no tuvieran aún autoridades propias constituidas.

Las normativas fueron las esperables en tal sentido, como por ejemplo las de exigirse las pertinentes autorizaciones para realizar el espectáculo; respetar los horarios, capacidad de público permitido y orden, entre otros asuntos.

Pero junto con estas disposiciones, llamativamente se hacía hincapié en la prohibición del uso de disfraces y/o máscaras fuera de la época carnestolenda.

"Los trajes de disfraz con que se cubra o desfigure el rostro, solo podrán ser permitidos el domingo anterior al carnaval, los tres días de este, y el de octava [...]" establecían los artículos 478 y 479 del Código, además de prohibirse los juegos con agua, harina y "otras materias sólidas" durante estas fiestas. ${ }^{32}$

Dentro de la tónica depuradora que este Código pretendía instaurar, no podían estar ajenos, además, aquellos temas que estaban más bien asociados a la "estética urbana" que al orden público en su sentido convencional.

Por ello es por lo que se promovió la sanción de quienes fuesen catalogados como vagos o mendigos, y que no pudiesen demostrar reales impedimentos para ganarse el sustento. Si alguien era frecuentador de pulperías, cafés, bodegones o sitios de recreo y no podía mostrar profesión u ocupación, ingresaba en la categoría de "vago". A su vez, solo podían mendigar aquellas "personas que por sus enfermedades o ancianidad estén imposibilitadas de procurarse subsistencia [...]", en cuyo caso, deberían inscribirse en el registro que llevaba la policía. ${ }^{33}$

Sin embargo, el Código preveía arresto de uno a diez días a aquellas personas que "ostentaran deformidades, heridas o enfermedades; las que se auto provoquen

\footnotetext{
${ }^{31}$ Art. N. ${ }^{4} 400$ del Código de Policía, 96.

${ }^{32}$ Y se agregaba: "Los que se disfracen deberán dar previamente su nombre a la policía, que los anotará en un registro especial y se entregará una tarjeta numerada para que el disfrazado la lleve sobre el traje en parte visible [...] No podrán usarse como disfraces, trajes eclesiásticos, uniformes del ejército o armada, $\mathrm{o}$ indecorosos de ninguna especie [...]”. Artículos N. ${ }^{\circ} 478$ y 479 del Código de Policía, Sección X, 96.

${ }^{33}$ Código de Policía, Sección IV, 90.
} 
lesiones; las que usen menores para inspirar lástima a los transeúntes [...]". ${ }^{34}$ Como puede apreciarse, no se escatimaban recursos punitivos ni siquiera en estos casos para intentar construir una sociedad "idealizada" en las mentes de quienes, aparentemente, no tenían un entero conocimiento del país real.

Y con respecto al ejercicio del meretricio, que era otra de las actividades encuadradas tácitamente dentro de las de recreación, debe decirse que en todo momento se notó la indisimulable incomodidad de optar entre regularla, ocultarla, camuflarla, y/o tolerarla, término este último que finalmente se impuso para definir a los establecimientos que ofrecían este servicio: las llamadas "casas de tolerancia".

Por ser justamente una actividad "tolerada", la ley 1532 de organización de los Territorios Nacionales facultó a los concejos municipales que fueran creándose, para reglamentar el funcionamiento de dichas casas. Y así lo hicieron. Pero en 1912, por un decreto del Poder Ejecutivo de fecha 08 de octubre se confirió también esta facultad a los gobernadores, para que intervengan en aquellos lugares en donde no había municipalidades ni Comisiones de Fomento. ${ }^{35}$

Así, esta práctica recibió distintos niveles de atención en los Territorios Nacionales, con erráticos intentos de supresión, ocultamiento, o reglamentaciones parciales, según las épocas. En el caso del Chaco, que es de donde disponemos el mayor caudal informativo, el problema no radicó tanto en el control de estas "casas", sino en el de la prostitución clandestina que, por su difusión, tempranamente se había convertido en un flagelo cuyas consecuencias negativas no eran ya analizables desde el punto de vista moral, sino fundamentalmente, sanitario. Basta con recordar que, en su conocido informe de 1914, el inspector Niklison había señalado:

Las enfermedades originadas en el contacto sexual están muy difundidas en el Chaco y Formosa, y la sífilis presenta aquí caracteres extremadamente graves, diseminada por la libre prostitución, e impuesta por la herencia. Difícilmente se encontrarán sujetos de cierta edad que no padezcan enfermedades venéreas... No hay atención sanitaria en los obrajes, y a esto se suma el abandono personal. El asunto merece empeñosa dedicación $\left[\ldots . .{ }^{36}\right.$

Pero como nuestra propuesta no es hablar de cuestiones sanitarias, sino fundamentalmente del sentido moralista que imperó en todas estas medidas tomadas desde principios de siglo $\mathrm{XX}$, necesariamente debemos centrarnos en las que tendieron a precisar mejor el funcionamiento de las casas "regenteadas", es decir, las "autorizadas", sobre las cuales podían realizarse efectivamente los controles.

En este sentido debe indicarse que, dadas las características de la época, las normativas sancionadas fueron sorprendentemente protectoras para las mujeres en general, y en particular las dedicadas a este oficio, y a su vez, severamente punitivas

\footnotetext{
${ }^{34}$ Código de Policía, Sección V, 91-92.

${ }^{35}$ Decreto Firmado por el presidente R. Sáenz Peña e Indalecio Gómez. Reyna 1039.

${ }^{36}$ Niklison 133.
} 
contra quienes ejercían la trata y/o fomentaban la corrupción de menores. Esto puede corroborarse a través de la lectura de las leyes números 4189 de 1903, y 9143 de 1913 por ejemplo. ${ }^{37}$

Tal vez, al haber sido sancionado entre estos años, el Código de 1908 reflejó en buena medida la tendencia que comenzaba a prevalecer sobre este tema. Posiblemente por ello, sus artículos se enfocaron en reafirmar las ya conocidas disposiciones de carácter moral y sanitario que estas "casas" debían tener en cuenta, a lo que se agregaban ahora las restricciones etarias para el trabajo de las internas y para el ingreso de los clientes, entre otros varios asuntos.

Se dispuso así, entre otras cosas, que estas "casas" no podrían establecerse a menos de dos cuadras de templos, plazas, teatros, escuelas, o sitios de reunión de la juventud. No podrían distinguirse entre las edificaciones circundantes, ni anunciarse expresa o indirectamente. No podrían trabajar en ellas menores de dieciocho años, ni darse entrada a menores de veintidós, pero lo llamativo del caso, era la facilidad que mostraba para el otorgamiento de los permisos de concesión, ya que se estipulaba que los pedidos debían efectuarse con una antelación de ocho días solamente para que la policía autorice el funcionamiento del local. ${ }^{38}$

De todos modos, en el Chaco por ejemplo esta actividad se mantuvo vigente durante la mayor parte de la etapa territoriana dados los altos porcentajes de masculinidad existentes, ${ }^{39}$ aunque los controles ciertamente evolucionaron con una periodicidad más regular y metodologías más eficaces, pese a las tibiezas o la aparente indiferencia de algunos gobernadores que, en ciertos casos, llegaron a regentear subrepticiamente tal actividad.

De todas formas, el verdadero control de estas "casas" fue ejercido por los municipios en las localidades que contaban con ellos. Dicho control se activó especialmente cuando las quejas de los parroquianos indicaban que la "actividad" había desbordado su perímetro autorizado, pero, sobre todo, cuando algún incidente o irregularidad hacía peligrar los ingresos impositivos obtenidos por el funcionamiento de estos locales. ${ }^{40}$

\footnotetext{
${ }^{37}$ Véase en amplitud el contenido de estas leyes en: Reyna 1038-1039.

${ }^{38}$ Código de Policía, Sección VI, 92-93.

${ }^{39}$ Solo a modo ilustrativo debe decirse que en 1914 había 133 hombres por cada 100 mujeres; en 1934, 131 hombres por cada 100 mujeres; y en 1947, 109 hombres por cada 100 mujeres. Si bien, como puede observarse, las proporciones tendieron a equilibrarse, el peso del género en una sociedad eminentemente rural es un elemento preponderante a la hora de evaluar el comportamiento y la inter-relación social de los grupos. Datos tomados de: (Ernesto J Maeder. Historia del Chaco, Colección Historia de Nuestras Provincias N. ${ }^{\circ}$ 18. (Buenos Aires, Plus Ultra, 1997) 210-211.

${ }^{40}$ Por ejemplo, en 1926 hubo un debate en la localidad de Sáenz Peña acerca del destino que debía darse al garito-prostíbulo local, que aportaba unos $800 \$$ de impuestos sobre los $2.788,33 \$$ que recaudaba el municipio en concepto de tributos mensuales. Ya desde principios de año la dirigencia local se debatía entre clausurarlo, o bien "subirle la patente, y evitar que garras extrañas se aprovechen [...]” (Sic). Periódico El Imparcial, Sáenz Peña, 24 de febrero de 1926, 4.
} 


\section{Los resultados de esta tendencia disciplinadora en los Territorios. El Chaco: un ejemplo representativo}

En este punto deberíamos detenernos un momento para analizar cuál fue la recepción y el uso que tuvieron estas normativas y Códigos y, sobre todo, cuáles fueron los resultados concretos de esta ofensiva reguladora del comportamiento público, que en esencia, fue copiada de sociedades de algunos países europeos. ${ }^{41}$

Y como habíamos comenzado el escrito con los ejemplos de las medidas tomadas en Capital Federal con base a la ley 4097, siguiendo luego con la sistematización de estas ideas en el Código de 1908, la lógica exigiría que hagamos un análisis de lo ocurrido con su aplicación en cada una de estas jurisdicciones. Pero ello no sería posible de realizar correctamente en esta ocasión sin desbordar el estrecho marco de un artículo. Sin embargo, y tal como lo preanunciáramos en el título del presente, es posible hacer una proyección general de lo acontecido en todos los ámbitos de aplicación si tomamos como ejemplo representativo a uno de los Territorios Nacionales. En tal sentido, creemos que el Chaco puede ser un adecuado modelo para ilustrar sobre el tema, puesto que este Territorio no solo tuvo un elevado porcentaje de las problemáticas que se querían combatir o evitar con estas medidas, sino que, además, fue también espacio de experimentación de algunas políticas de direccionamiento y control social que se aplicarían luego en el resto de las jurisdicciones federales periféricas. Lo acontecido en Chaco puede, por tanto, proyectarse sin aprehensiones al conjunto de los Territorios Nacionales. Pero para poder dimensionar alcances y aplicación de estas normativas en un Territorio que estuvo expuesto a bruscos cambios demográficos, necesariamente debemos recordar su proceso de poblamiento, aunque sea sintéticamente. En la primera década del siglo XX, período en el cual ya están en vigencia las leyes y Códigos mencionados, el Territorio del Chaco se hallaba poblado por gente blanca únicamente en su porción oriental, a la vera de los grandes ríos del Este (Paraná y Paraguay). Allí fue donde comenzó la colonización europea en 1878 y para este momento ya se hallaban consolidadas su capital (Resistencia) y algunas localidades cercanas. Se contaban 21.000 habitantes en total según el censo de 1905, pero la mayor parte del territorio hacia el norte, centro y oeste no había sido ocupada aún. Esta amplia superficie se hallaba todavía habitada por tribus originarias.

Entre los inmigrantes externos de entonces, -y excluyendo al numeroso grupo de paraguayos-, la población blanca europea se integraba con una mayoría de italianos y españoles, quienes al poco tiempo de residencia pasaron a tener roles protagónicos en diversos ámbitos de esta incipiente sociedad, y desde luego, tempranamente comenzaron a fundar sus asociaciones de ayuda mutua. Todo este conjunto de pioneros estuvo directa o indirectamente relacionado a las entonces actividades predominantes: producción agrícola en las colonias fundadas en las cercanías de Resistencia, pero fundamentalmente, la actividad forestal, a través de la extracción de madera, y sobre todo, de la producción de tanino.

\footnotetext{
${ }^{41}$ Decimos esto porque cada vez que hubo debates sobre los alcances de ciertas medidas, se invocaba su puesta en práctica en países como Inglaterra y, sobre todo, Francia.
} 
En 1908, año de la publicación del Código descripto, se sanciona la ley de "Fomento de los Territorios Nacionales", que en el caso del Chaco tuvo una importancia crucial, ya que por ella se autorizó el tendido de vías férreas que permitirían incorporar el espacio interior, y adicionalmente, la ampliación de la frontera agrícola.

Para 1914 la obra estuvo terminada; nuevas campañas militares pacificaron a los nativos y en parte los ubicaron en Reducciones, de modo que al año siguiente esta gran superficie ya estaba bajo control efectivo del Estado Nacional.

La incorporación prácticamente inmediata de pobladores blancos en las áreas circundantes a las recién habilitadas estaciones ferroviarias, y la fundación de pueblos en sus adyacencias completaría esta ocupación "relámpago" del interior del Chaco, y para 1915, la población total ya ascendía a 46.000 habitantes.

Se iniciaba así una nueva etapa para este Territorio Nacional cuyo ascenso económico y demográfico se potenciaría exponencialmente al poco tiempo con el dictado del decreto presidencial de 1921 que liberaba tierras fiscales a la colonización, y que coincidió con el descubrimiento de las posibilidades exitosas del cultivo de algodón en el reciente espacio ganado, casi en simultáneo con el súbito incremento del precio internacional de este textil. ${ }^{42}$

Esta combinación de factores fomentó una fuerte atracción inmigratoria externa e interna. Por la primera ingresaron casi 15.000 inmigrantes entre los años 1920 y 1930 provenientes fundamentalmente de la Europa del Este en esta nueva etapa colonizadora. Por la segunda, un promedio anual de 29.000 trabajadores manuales provenientes de las provincias vecinas aportó su fuerza laboral a las demandas de este nuevo ciclo económico que se inició vertiginosamente, y que se denominó ciclo algodonero, para distinguirlo del ciclo forestal, predominante en los años anteriores.

Por esos años, el crecimiento demográfico del Chaco no solo fue exponencial, sino también muy repentino, llegando a decuplicar su población en lapsos muy cortos y con incrementos de hasta un 11\% anual, colocándose entre las jurisdicciones más efervescentes del país. También se fue construyendo la imagen de un Chaco "gringo", en virtud de la "impresión cromática" que causaba la alta densidad de inmigrantes rubios en algunas zonas en particular.

Estos inmigrantes europeos a su vez, y al igual que sus coterráneos de la primera etapa pobladora, fueron fundando también sus propias sociedades mutualistas

\footnotetext{
${ }^{42}$ El decreto del Poder Ejecutivo Nacional del 11 de julio de 1921 dispuso la creación de varias colonias agrícolas y pastoriles en el Chaco, con lo cual se produjo una magnífica oferta de tierras para la producción. Simultáneamente a estas medidas se produjo en EE.UU la crisis algodonera causada por la invasión de la plaga del picudo, lo cual hizo elevar considerablemente los precios internacionales del textil. Casi inmediatamente, el ministro de agricultura Le Bretón realizó en 1923 una campaña para fomentar el cultivo algodonero y atraer inmigración. Estos alicientes provocaron una gran afluencia de pobladores a este Territorio Nacional.
} 
en este nuevo espacio, y cuya importancia decisiva podremos valorar seguidamente en directa relación al tema que nos ocupa.

Ahora bien, ¿qué buscamos explicar con esta introducción? Con las descripciones previas procuramos anticipar que el destino de las normativas pensadas para moldear sobre todo a las nacientes sociedades de los Territorios Nacionales estuvo marcado prácticamente desde su puesta en vigor, y ese destino fue una obsolescencia prematura.

Es que los vertiginosos cambios económicos y sobre todo demográficos ocurridos en general en varios Territorios Nacionales durante la segunda y tercera década del siglo XX, hicieron poco menos que impracticables a todo este conjunto de medidas, básicamente porque los cuerpos sociales que aquí se formaron, estuvieron expuestos a procesos muy abruptos de movilidad y transformación. Y lo ocurrido en Chaco fue un ejemplo elocuente de esta dinámica. ¿Y de dónde vendría entonces la necesaria labor orientadora y contenedora, así como la tarea de construcción de tácitas normas de convivencia colectiva?

Sin menoscabar la incidencia del periodismo gráfico, ni la fundamental función de la escuela pública, debe advertirse sin embargo que la primera estuvo limitada a un restringido grupo de lectores alfabetizados de los núcleos urbanos, y la segunda, si bien tuvo notable influencia sobre todo a partir de los años treinta, solo repercutió inicialmente en los infantes, y sus resultados en este plano se verían recién en el largo plazo.

Aquí es entonces en donde debemos dimensionar el importantísimo papel que tuvieron las nacientes entidades y asociaciones civiles de ayuda mutua, las cuales, independientemente de sus funciones específicas, cumplieron una tarea que contribuyó a hacer un poco menos requerida la presencia del Estado en estas cuestiones particulares, y consecuentemente también, menos necesarias las reglamentaciones paternalistas para garantizar la convivencia entre grupos humanos muy distintos.

Durante la segunda y tercera década del siglo XX las diversas fuerzas vivas territorianas fueron ganando un ascendiente protagonismo y como consecuencia indirecta de sus acciones, se puso en evidencia el anacronismo de la tutela estatal en materia de medidas de orientación social, e inclusive, en materia política. El régimen de minoridad establecido para estas jurisdicciones empezaba a mostrar sus limitaciones y obsolescencia, y se hacían necesarios algunos cambios en la relación entre los poderes centrales y estas jurisdicciones periféricas.

En el caso particular de Chaco, su demografía y cuerpo social habían cambiado sustancialmente en un tiempo muy breve. Hemos visto sintéticamente lo acontecido entre 1908 y 1921 (solo trece años), de modo que, reglamentaciones como las que hemos analizado quedaron prácticamente inútiles a poco de nacer, a tal punto que durante la década del veinte ya no eran casi mencionadas en las actuaciones referidas a contravenciones. Para los procedimientos inherentes generalmente se apelaba al viejo 
Código Rural de 1894; a lo establecido por las ordenanzas municipales o de Comisiones de Fomento, o sencillamente se buscaba respaldo en lo estipulado por los estatutos de las asociaciones mutualistas, las cooperativas agrarias, o los clubes deportivos, cuando el objetivo era controlar, por ejemplo, espectáculos de alta concurrencia.

A la sazón, debe decirse que estas últimas entidades ganaron autonomía, poder de convocatoria y una fuerte presencia a partir de la década del veinte, llegando a convertirse en los más importantes centros de sociabilidad, y en gran medida, espacios formadores de conductas colectivas, relegando a un lugar secundario a las instituciones del Estado, en el caso de que estas existieran. Así, y sin que estos fueran sus objetivos principales, las Sociedades de Socorros Mutuos e incluso las Cooperativas Agrícolas desempeñaron exitosamente el rol de núcleos de inclusión e integración social en el Chaco.

Las Sociedades Mutualistas fueron las primeras organizaciones que posibilitaron intercambios interétnicos en el Chaco, y a la sazón, varias de ellas se fundaron tempranamente. Tal vez esté demás señalar que entre las primeras entidades de este tipo estuvieron las de los italianos y españoles, por ser las colectividades mayoritarias afincadas durante la primera etapa inmigratoria.

Pero durante la segunda etapa, y particularmente en la zona central del Territorio, luego de las ya instaladas entidades de españoles e italianos, una de las primeras instituciones fundadas -vinculadas esta vez a los nuevos contingentes arribados- fue la de los checoslovacos, constituida en Sáenz Peña bajo el nombre de Slavia en el año 1917. Luego surgirían otras como la Unión Germánica en Charata (1920); la Sociedad Húngara de Cultura y Socorros Mutuos en Villa Angela (1931).

Otros centros culturales y de beneficencia fueron, por ejemplo, los que se erigieron en la colonia La Montenegrina en 1927, o la de los Búlgaro Macedónicos en 1929, en Las Breñas. Posteriormente nacerían las asociaciones pertenecientes a los búlgaros y yugoslavos en Sáenz Peña, aunque lo harían bastante más tarde. Estas instituciones cumplieron sobradamente el propósito para el cual fueron creadas, y en general, tuvieron una política de puertas abiertas hacia quienes no eran parte de la colectividad respectiva.

Pero aparte de estas, fue también muy relevante la labor de las asociaciones civiles que se constituyeron -a veces de manera espontánea- para impulsar iniciativas o cubrir servicios que los organismos del Estado no alcanzaban a satisfacer por ineficacia o distancia. Precisamente estas acciones grupales contribuyeron indirectamente a desarrollar vínculos sociales mediante la participación común en actividades de recreación y esparcimiento orientadas, por lo general, a la recaudación de fondos para obras de bien público.

A partir de la década del veinte fue muy frecuente, por ejemplo, la organización de romerías, kermeses y bailes para construir instalaciones deportivas, sanitarias, o de seguridad, y al tener la recaudación un destino comunitario, se publicaban sus 
resultados en los periódicos locales. Ello nos permite conocer hoy, entre otras cosas, algunas modalidades de sociabilidad de los parroquianos.

En lo que respecta a las Cooperativas Agrícolas, las primeras instituciones de este tipo surgieron en el Chaco en su zona oriental, también como consecuencia de la acción de los pioneros de la primera corriente inmigratoria.

Ya en la segunda etapa de afluencia y en buena medida como parte del auge algodonero, se expandirían en la zona central y sudoeste del Territorio. A partir de 1925 se multiplicaron estas entidades, llegando a 16 en 1934; a 24 en 1940, y a 32 a finales de esa década. En un alto porcentaje se instalaron en los departamentos que concentraron en este momento el mayor volumen de la masa inmigratoria, es decir Campo del Cielo y Napalpí, y como era de esperar, dichas instituciones llegaron a asociar al 75\% de los agricultores, incluyendo -sin distinción-, a criollos e inmigrantes de diferentes orígenes. ${ }^{43}$

Además de las funciones específicas de proteger los intereses de sus asociados, estas cooperativas actuaron como centros vinculantes de la masa social ligada a ellas. Por haber conocido esta realidad in situ, coincidimos con la descripción que hiciera el historiador chaqueño Guido Miranda al referirse, por ejemplo, al evento excepcional que representaban las asambleas anuales de estas entidades, las que por sus características, fueron un inmejorable espacio de vinculación social entre grupos que normalmente no tenían muchas posibilidades de contacto, sobre todo entre la totalidad de los integrantes familiares. ${ }^{44}$

De esta forma, además de la función económica que cumplieron estas asociaciones, indudablemente desempeñaron un rol no menos importante como centros de interrelación cultural y social en ámbitos en los cuales los puntos de contacto colectivo no abundaron. En estos espacios llegaron a forjarse sólidas amistades entre criollos y gringos, y con frecuencia, fueron también el entorno ideal para propiciar el nacimiento de lazos parentales derivados de las relaciones entabladas entre las nuevas generaciones.

Pero con todo, y al margen del espíritu solidario y de construcción colectiva que caracterizó a los pioneros, la acción desplegada por estas entidades mutualistas no pudo ocultar la verdadera causa que propició que este asociacionismo evolucionara hasta exceder sus objetivos originales. Dicha causa fue la inconsecuencia del Estado

\footnotetext{
${ }^{43}$ Hugo Beck, "Inmigrantes Europeos en el Chaco". Cuadernos de Geohistoria Regional 39 (2001): 112.

${ }^{44}$ Decía Miranda: "Hay un día en el año en que se paralizan los trabajos en las chacras; toda la familia, inclusive los peones, se acicala con la mejor vestimenta y parte -en carros, sulkys o volantas- para asistir a un acto que tiene lugar en el pueblo, y que dura desde la mañana hasta altas horas de la noche: es la Asamblea Anual Ordinaria de la Cooperativa. Siempre hemos contemplado con emoción estas vastas asambleas públicas, celebradas en los galpones de zinc que sirven para almacenar la fibra o la semilla de algodón. Son un acontecimiento característico del Chaco: cientos de socios de la más heterogénea condición; agricultores, viejos, hijos, o viudas que siguen con la labor, se reúnen a discutir intereses comunes a pesar de las diferencias de idioma, origen, situación, educación, o temperamento" Guido Miranda Tres Ciclos Chaqueños. Crónica Histórica Regional. (Resistencia-Chaco, Editorial Norte Argentino, 1955) 259-260.
} 
en la conducción del poblamiento de estas jurisdicciones. Un Estado que promovió los procesos, pero que luego no pudo controlarlos ni atenderlos eficazmente en todas sus variantes, a lo cual se añadió una codificación incompleta, extemporánea, o idealista, y un inesperadamente rápido envejecimiento de la ley 1532 de organización de los Territorios Nacionales.

La misma, concebida para mantener por mucho tiempo a estas jurisdicciones bajo un régimen de minoridad tutelada, no fue cumplida en todos sus términos originales ni actualizada debidamente, por lo que no se alcanzó a calcular los efectos de la vertiginosa evolución que tendrían algunas de ellas, y antes de lo previsto, ya se notaba la necesidad de producir reformas fundamentales en estos espacios territoriales.

$\mathrm{Y}$ aunque estas ideas ya germinaban a fines de los años veinte, y se galvanizarían en la siguiente década, solo empezarían a transformarse en hechos concretos recién a comienzos de los años cincuenta, cuando se inició el proceso de conversión a provincias de algunos Territorios Nacionales, y con ello, el acceso a una ciudadanía plena para sus habitantes.

\section{A modo de conclusión}

A comienzos del siglo XX y casi en vísperas del Centenario, en Argentina pudieron observarse, con bastante nitidez, algunas políticas tendientes a diseñar a una sociedad que, integrada con un alto componente inmigratorio, todavía se hallaba en vías de formación. Dichas políticas -o al menos, intenciones-, se inscribieron en el marco de la admiración que la entonces dirigencia nacional de "notables" profesaba por el funcionamiento y las sociedades de algunos destacados países europeos.

Desde luego, la implementación de reformas orientadoras debía hacerse necesariamente a través de la imposición de leyes y reglamentos que direccionaran al cuerpo social hacia la adopción y práctica de normas de coexistencia compatibles con las vigentes en aquellas sociedades que se buscaba emular.

Dadas las autonomías, y sobre todo los arraigados tradicionalismos existentes en las antiguas provincias constituidas, los ámbitos de aplicación de las eventuales reformas debían ser necesariamente las jurisdicciones federales, únicos espacios en donde había una incumbencia directa de los poderes centrales, y en donde, además, aún no se habían consolidado las identidades colectivas.

A la sazón, estos espacios federalizados eran los que -proporcionalmente-, habían recibido y/o estaban recibiendo mayor porcentaje de inmigración europea, por lo cual, la Capital Federal con su gran cosmopolitismo, y los Territorios Nacionales con sus nuevos y heterogéneos cuerpos sociales, constituían los escenarios propicios para encarar un ensayo modelador de hábitos y costumbres acordes a los ejemplos de los países más admirados del viejo continente. 
Para efectivizar este experimento, el campo de intervención debía estar inicialmente vinculado a las actividades de recreación y esparcimiento, por cuanto era precisamente allí en donde podían detectarse mejor las conductas públicas (y sus desviaciones), y proceder correctivamente.

Por esta razón se elaboraron y pusieron en vigor leyes y Códigos contravencionales cuyos propósitos principales serían los de prohibir, restringir, y penalizar prácticas lúdicas, costumbres o actividades de recreación que no se encuadraran dentro de la tónica marcada por los poderes centrales, o que no coincidieran con los modelos de comportamiento y moralidad foráneos que se deseaba imponer.

Estas normativas, por tanto, tuvieron un sesgo disciplinador algo exagerado, en ciertos casos hasta absurdo, y ciertamente discordante con la realidad de los cuerpos sociales y las costumbres existentes en el país. Dichas discordancias generaron recurrentes controversias sobre su validez, y también, limitadas posibilidades de aplicación en los respectivos ámbitos de destino, y casi una inmediata obsolescencia en algunos Territorios Nacionales debido a sus vertiginosas transformaciones socioeconómicas.

De este modo, esta tarea orientadora del comportamiento público recayó casi de hecho en las propias asociaciones civiles de estas jurisdicciones las cuales, sin proponérselo como objetivo principal, suplantaron en buena medida la acción del Estado en la función de inclusión, integración y formación de conductas colectivas, poniendo en evidencia la ineficacia y el anacronismo del tutelazgo central en estas materias.

De alguna manera, la acción común de estas asociaciones, cuya eficacia pudo comprobarse especialmente en el Territorio Nacional del Chaco, puso de manifiesto cierta madurez alcanzada tempranamente por estos cuerpos sociales, lo cual, además de hacer inviable la vigencia de normativas de tipo paternalista, preanunció en cierta forma el advenimiento de una nueva etapa en la situación institucional de los Territorios Nacionales.

\section{Bibliografía}

\section{Fuentes primarias}

Código Rural para los Territorios Nacionales; Recopilación realizada por Máximo Reyna, 1902-1910. Ministerio del Interior, Bs.As., 1910.

Código Rural de los Territorios Nacionales. Nueva edición con las modificaciones introducidas por las leyes de 16 de septiembre de 1910, y 28 de febrero de 1917, Buenos Aires, J. Lajouane \& Cía Editores, 1922.

Código de Policía para los Territorios Nacionales de la República Argentina, Buenos Aires, Imprenta de Juan Alsina, 1908. 
La ofensiva moralizadora y de control social en los espacios federales argentinos...

Memorias de los gobernadores del Territorio Nacional del Chaco 1900-1905, Resistencia, IIGHI-Conicet.

República Argentina. Archivo General de la Nación (AGN). Memoria del Ministerio del Interior 1919-1920, inédita, p. 338.

República Argentina. Tercer Censo Nacional 1914., Tomo V. Bs. As., Talleres Gráficos. Rosso, 1917.

República Argentina. Ministerio del Interior. Asesoría Letrada de Territorios Nacionales. Censo General de los Territorios Nacionales, 1920. Tomo 1. Bs. As., Establecimiento Gráfico A de Martino, 1923.

República Argentina, Informe del Inspector del Departamento del Trabajo, José Elías Niklison, Boletín del Departamento Nacional del Trabajo nº 32, 1915, p. 4-147.

Reyna, Máximo, Territorios Nacionales. Leyes y decretos sobre su administración y resoluciones varias aplicables a los mismos, Buenos Aires, Ministerio del Interior, 1910.

\section{Prensa}

El Imparcial, (Sáenz Peña) 1925.

\section{Fuentes secundarias}

\section{Libros}

Beck, Hugo. Inmigrantes Europeos en el Chaco. Transición del pluralismo al crisol. Cuaderno de Geohistoria Regional n`39. Resistencia, Chaco: IIGHI-CONICET, 2001.

Borrini, Héctor. La Colonización como Fundamento de la Organización Territorial del Chaco (1930-1953). Cuadernos de Geohistoria Regional No. 19. Resistencia: IIGHI-CONICET, 1987.

Linares Quintana, Segundo. Derecho Público de los Territorios Nacionales, Argentino y Comparado, prólogo de Alfredo Palacios. Buenos Airtes: S.edit, 1937.

Maeder, Ernesto. Historia del Chaco. Colección Historia de Nuestras Provincias $\mathrm{n}^{\circ}$ 18. Buenos Aires: Plus Ultra, 1997.

Mari, Oscar Ernesto. Inseguridad y Bandidaje en el Territorio Nacional del Chaco 1918-1940. Cuaderno de Geohistoria Regional no 30. Resistencia: Instituto de Investigaciones Geohistóricas, CONICET, 1994. 
Miranda, Guido. Tres Ciclos Chaqueños. Crónica Histórica Regional. ResistenciaChaco: Editorial Norte Argentino, 1955.

Polich De Calvo, Lidia. Hombres y Mujeres que Hicieron Chaco. Encarnación, Paraguay: Editorial Talleres Gráficos de Imprecop, 1996.

Ruffini, Martha. La Pervivencia de la República Posible en los Territorios Nacionales. Poder y ciudadanía en Río Negro. Buenos Aires: Universidad Nacional de Quilmes, 2007.

Schaller, Enrique. La Colonización en el Territorio Nacional del Chaco en el período 1869-1921 En: Cuadernos de Geohistoria regional No12. Corrientes: IIGHICONICET, 1986.

Suáiter Martínez, Francisco. Los Territorios. Buenos Aires: Instituto Cultural Joaquín V. González, 1943.

\section{Artículos de revistas}

Bandieri, Susana. "Cuando crear una identidad nacional en los territorios patagónicos fue prioritario". Revista Pilquen 11 (2009): 1-5.

Martin, María Haydée. "El Código Rural de los Territorios Nacionales (1894)". Instituto de Historia del Derecho Ricardo Levene 8 (1980): 165-196. 